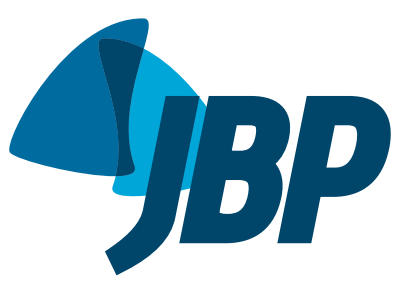

1. Facultad de Ciencias de la Salud, Universidad Pública de Navarra, Navarra, España.

2. Servicio de Neumología, Complejo Hospitalario de Navarra, Navarra, España.

Submitted: 29 March 2017 Accepted: 3 September 2017.

Study carried out at the Facultad de Ciencias de la Salud, Universidad Pública de Navarra, and in the Servicio de Neumología, Complejo Hospitalario de Navarra, Navarra, España.

\section{Effects of simple long-term respiratory care strategies in older men with COPD}

Fabrício Zambom-Ferraresi1 ${ }^{1}$, Pilar Cebollero², Javier Hueto², María Hernández², José Cascante ${ }^{2}$, María Milagros Antón ${ }^{1}$

\begin{abstract}
Objective: To evaluate a 24-month supervised, community-based maintenance exercise program after 3 months of pulmonary rehabilitation (PR) in comparison with a 27-month physical activity counseling program, in terms of the effects on maximal muscle strength, muscle power output, and exercise capacity, in individuals with COPD. Methods: Sixtythree men with moderate-to-severe COPD were recruited from two previous studies. Of those 63 participants, 31 were offered 3 months of PR followed by a 24-month supervised maintenance exercise program (24MME group) and 32 were offered a $27-$ month physical activity counseling program (27MPAC group). Measurements at 3 months and at the end of the study period included maximal strength of the upper and lower limbs, power output of the lower limbs, six-minute walk distance (6MWD), and quality of life. Results: At 27 months, the improvements in maximal strength of the upper and lower limbs were greater in the 24MME group than in the 27MPAC group (37.6 \pm $28.3 \%$ and $28.4 \pm 13.3 \%$, respectively, vs. $8.8 \pm 16 \%$ and $13.6 \pm 16.4 \%$, respectively; $\mathrm{p}<0.05)$, as was the improvement in power output of the lower limbs $(24.6 \pm 18.4 \%$ vs. $-2.3 \pm 28.5 \% ; p<0.01)$. The increase in the 6MWD after 3 months was also greater in the 24MME group than in the 27MPAC group $133.2 \pm 36.6 \mathrm{~m}$ vs. $2.9 \pm 34.7 \mathrm{~m} ; \mathrm{p}$ $<0.05)$, although there were no differences between the two groups in terms of the $\triangle 6 \mathrm{MWD}$ at 27 months (vs. baseline). Conclusions: A supervised, community-based maintenance program is a successful long-term strategy to preserve the benefits of PR on peripheral muscle function and exercise capacity in individuals with COPD. However, physical activity counseling can maintain maximal muscle strength and exercise capacity in such individuals.
\end{abstract}

Keywords: Pulmonary disease, chronic obstructive; Muscle strength; Leg/physiology, Muscle, skeletal/physiology; Physical fitness; Exercise therapy/methods.

\section{INTRODUCTION}

One strategy to promote long-term health-enhancing behavioral changes, resulting in improvements in dyspnea, exercise capacity, and health-related quality of life, as well as to maximize skeletal muscle function, in older adults with COPD is the use of a maintenance exercise program after pulmonary rehabilitation (PR). However, the effectiveness of such programs is not well established, because of their heterogeneity in terms of duration, components, exercise intensity, and level of supervision. (1-5) Another short- and long-term strategy, which might be a more economical and feasible approach to improving exercise capacity and quality of life in COPD patients, is the use of a physical activity counseling program. ${ }^{(6)} \mathrm{A}$ few studies have examined the benefits of long-term PR maintenance programs, ${ }^{(1,2,4,5,7)}$ and one study ${ }^{(6)}$ examined the longterm effects of a physical activity program. However, to our knowledge, there have been no studies comparing a long-term supervised maintenance exercise program and a long-term physical activity counseling program in terms of their effects on exercise capacity and quality of life in older individuals with COPD.
The peripheral muscle dysfunction of the lower limbs observed in patients with COPD is characterized by a reduction in maximal muscle strength and a loss of muscle mass, which also occur during the milder stages of the disease. ${ }^{(8)}$ Aging is known to be associated with decreases in muscle mass, maximal strength, and muscle power. ${ }^{(9)}$ Maximal strength peaks in the third decade of life, ${ }^{(10)}$ remains unchanged or decreases slightly from approximately 40 years of age ${ }^{(11)}$ into the fifth decade, declining more rapidly (at a rate of $12-15 \%$ per decade) thereafter. ${ }^{(10,12)}$ This muscle weakness and muscle atrophy result in functional limitations and are associated with increased mortality. ${ }^{(13)}$ Recently, muscle power has emerged as a discriminative variable for understanding the reduction in mobility and in the ability to perform activities of daily living. ${ }^{(14)}$ In older adults, physical inactivity might be one of the mechanisms of this peripheral muscle dysfunction. ${ }^{(15)}$ Nevertheless, few studies have examined the effects that long-term strategies of maintenance exercise or physical activity counseling have on muscle strength and muscle power output in individuals with COPD. ${ }^{(7)}$ Therefore, the primary aim of the present study was to compare a community-based maintenance exercise

Correspondence to:

María M. Antón. Facultad de Ciencias de la Salud, Universidad Pública de Navarra, Campus de Tudela, Avenida de Tarazona, s/n, 31500, Tudela, Navarra, España. Tel.: 34 948417877. Fax: 34 948417892. E-mail: milagros.anton@unavarra.es

Financial support: This study received financial support from the Spanish Ministry of Education and Science (Plan Nacional I+D+i 2008-20011; Strategic action:

"Sport and physical education" Ref: DEP2011-30042). 
program, applied for 24 months after 3 months of PR, and a physical activity counseling program, applied for 27 months, in terms of their effects on maximal dynamic strength, muscle power output, exercise capacity, and quality of life in older adults with COPD. We hypothesized that, in older adults with moderateto-severe COPD, a supervised maintenance exercise program after PR would maintain the improvements in functional capacity, muscle function, and health-related quality of life better than would the physical activity counseling program.

\section{METHODS}

This was a retrospective, non-randomized study designed to compare the impact that two different treatments have on exercise capacity, muscle function, and health-related quality of life in older adults with COPD. The sample consisted of 63 men with stable, moderate-to-severe COPD who were recruited from pulmonology consultations. The participants were enrolled in one of two programs: a 3-month PR program, followed by a 24-month community-based maintenance exercise program (24MME group, $\mathrm{n}=31$ ); and a 27-month physical activity counseling program (27MPAC group, $\mathrm{n}=32$ ).

The inclusion criteria were as follows: being male; having been diagnosed with moderate-to-severe COPD, characterized by an $\mathrm{FEV}_{1} / \mathrm{FVC}$ ratio $<0.70$ and a postbronchodilator $\mathrm{FEV}_{1}$ value $30-80 \%$ of the predicted value, corresponding to stage II or III according to the Global Initiative for Chronic Obstructive Lung Disease criteria(16); showing grade 2 or 3 (symptomatic) dyspnea, as defined by the Modified Medical Research Council scale score; and being over 50 years of age. Current smokers were excluded, as were individuals who had experienced an exacerbation of COPD in the last 3 months, those who suffered from uncontrolled heart disease, and those who had been diagnosed with neoplasia in the last 5 years, as well as those with any neuromuscular, musculoskeletal, or joint disorders that might limit their exercise capacity.

The research was conducted in accordance with the World Medical Association Declaration of Helsinki for medical research involving human subjects, and the study was approved by the Committee on Ethics, Animal Experimentation, and Biosafety of the Public University of Navarre, in Navarra, Spain (Protocol no. PI-002-112). All participants gave written informed consent.

Participants were tested at baseline, at 3 months, and at the end of the study period. All underwent spirometry, with determination of lung volumes by body plethysmography and of the DLCO. (16) In addition, anthropometric variables were assessed, as was the distance walked on the six-minute walk test, or six-minute walk distance (6MWD), ${ }^{(17)}$ which was used in order to evaluate functional and exercise capacity.

The Chronic Respiratory Questionnaire (CRQ) was used in order to assess the health-related quality of life. (18) The CRQ is a disease-specific instrument evaluating four domains (on a scale of 1 to 7), and the Spanish-language version has been validated for use in Spain. ${ }^{(19)}$ The minimal clinically significant difference is defined as a mean improvement of 0.5 per domain. ${ }^{(19)}$

The production of muscle force by the upper and lower limbs was examined. The participants were familiarized with the strength tests. Maximal dynamic strength, based on the one-repetition maximum (1RM), was assessed on a commercial machine (Technogym, Gambettola, Italy) and was defined as the load displaced in the bilateral leg press exercise, in which the knees and hips were flexed at $90^{\circ}$ and $45^{\circ}$, respectively. On the day of the test, the participant warmed up during a 5-min period of walking and stretching exercises. In addition, several warm-up contractions for the leg press exercise were performed. Thereafter, four to five attempts were made in order to determine the 1RM. The maneuvers were performed separately, with a break of 2 min between each attempt. The 1RM was defined as the last extension accepted as valid, performed with the maximum load.

After determination of the 1RM values, the muscle power output in the leg press exercise was measured. The muscle power of the extensor muscles of the leg and hip was measured during the concentric phase of the bilateral leg press exercise, the weight (in $\mathrm{kg}$ ) corresponding to the load at $50 \%$ of the $1 \mathrm{RM}$. The participants were instructed and encouraged to displace the weights as rapidly as possible. Two trials were performed, with 2 min of recovery between attempts. The best of the two was used for further analysis. ${ }^{(20)}$

The bilateral maximum dynamic strength (1RM) of the upper limb muscles was examined via the seated chest press exercise. To avoid the influence of fatigue on the 1RM values, the maximal load was determined in four to five attempts with a 2-min recovery period between attempts. The 1RM was defined as the last extension accepted as valid, performed with the maximum load.

During the initial 3-month period, participants in the 24MME group completed an outpatient PR program, as described elsewhere. ${ }^{(21)}$ Upon completion of the PR program, a pulmonologist invited each 24MME group participant to receive the maintenance exercise intervention at a recreational sport facility. The maintenance exercise program consisted of two non-consecutive, multi-component, supervised training sessions per week over a 24-month period, with four-month gaps during the summer (school vacation) breaks. Each training session was 90 min long and comprised the following components: exercises of balance and proprioception; 20-30 min of walking at moderate intensity $(87.5-100 \%$ of the maximum heart rate achieved during the six-minute walk test); and strength training (with free weights) that included the sit-to-stand exercise, supine chest press, biceps exercises, and the seated row at moderate intensity (3 sets, $6-12$ repetitions, at $40-70 \%$ of the 1 RM). 
Heart rate and $\mathrm{SpO}_{2}$ were monitored throughout the sessions. All sessions were supervised by an exercise physiologist. During the summer breaks, the participants were encouraged to remain as physically active as possible.

The participants in the 27MPAC group enrolled in the 27-month physical activity counseling program, which consisted of a recommendation of walking at least 3 times weekly for at least 30 min each time. Participants recorded the number of times that they walked per week and their walking duration (in minutes per day) in a diary. In addition, they received a structured telephone call once a month from the same nurse with whom they had interacted during the pulmonology consultations. This phone call consisted of a brief introductory conversation followed by the administration of a questionnaire to collect the diary information.

Statistical analyses were performed with the SPSS Statistics software package for Windows, version 20.0 (IBM Corporation, Armonk, NY, USA). The assumption of a normal distribution of the data was evaluated with the Shapiro-Wilk test. Baseline differences between the groups were compared via unpaired Student's t-test or via the Mann-Whitney U test for non-normally distributed data. The intervention-related effects were assessed using two-way repeated-measures ANOVA (group vs. time). For each group, the differences between variables over time (time effect: from baseline to 3 months and to the end of the study period) were evaluated by using pairwise comparisons with Bonferroni correction or the Friedman test for non-normally distributed variables. For non-normally distributed variables, the data were $\log _{10}$-transformed. If the data still had non-parametric characteristics, a non-parametric statistical technique was used. Selective relative changes (proportional or absolute changes) between the groups were assessed with unpaired t-tests or with the Mann-Whitney $U$ test for non-normally distributed variables. The values in the text, tables, and figures are reported as the mean and standard deviation. The level of statistical significance was set at $p<0.05$.

\section{RESULTS}

Sixty-three participants were recruited for this study: 31 in the 24MME group and 32 in the 27MPAC group. In the 24MME group, 3 participants dropped out after the 3 months of the PR program, 6 participants refused to continue the maintenance program, 8 dropped out of the maintenance program due to clinical worsening, and 2 died during the 24-month intervention period. In the 27MPAC group, 2 participants dropped out after 3 months, and 6 dropped out before the end of the intervention period (Figure 1). The anthropometric and pulmonary function characteristics of the participants are shown in Table 1 . No significant differences between the groups were found at baseline for any of the variables measured, except for the 6MWD and lower-limb muscle power output at $50 \%$ of the 1 RM.

Between the study outset (baseline) and the end of the study period, the maximal strength on the leg press exercise increased by $28.4 \pm 13.3 \%$ in the $24 \mathrm{MME}$ group (from $203.6 \pm 45.7 \mathrm{~kg}$ to $262.5 \pm 70.3 \mathrm{~kg}$; $\mathrm{p}$ $<0.001$ ) and by $13.6 \pm 16.4 \%$ in the 27 MPAC group (from $222.3 \pm 82.1 \mathrm{~kg}$ to $251.1 \pm 88.3 \mathrm{~kg} ; \mathrm{p}<0.01$ ), as shown in Figure 2. The magnitude of improvement was greater in the 24MME group than in the 27MPAC group ( $p<0.05$ ). Figure 2 also shows that, between those same two time points, muscle power output increased by $24.6 \pm 18.4 \%$ in the $24 \mathrm{MME}$ group (from $725.5 \pm 163.9 \mathrm{~W}$ to $897.1 \pm 211.6 \mathrm{~W} ; \mathrm{p}<0.05)$ and decreased by $2.3 \pm 28.5 \%$ in the 27 MPAC group (from $659.7 \pm 287.1 \mathrm{~W}$ to $625.4 \pm 298.8 \mathrm{~W} ; \mathrm{p}=0.77)$. The

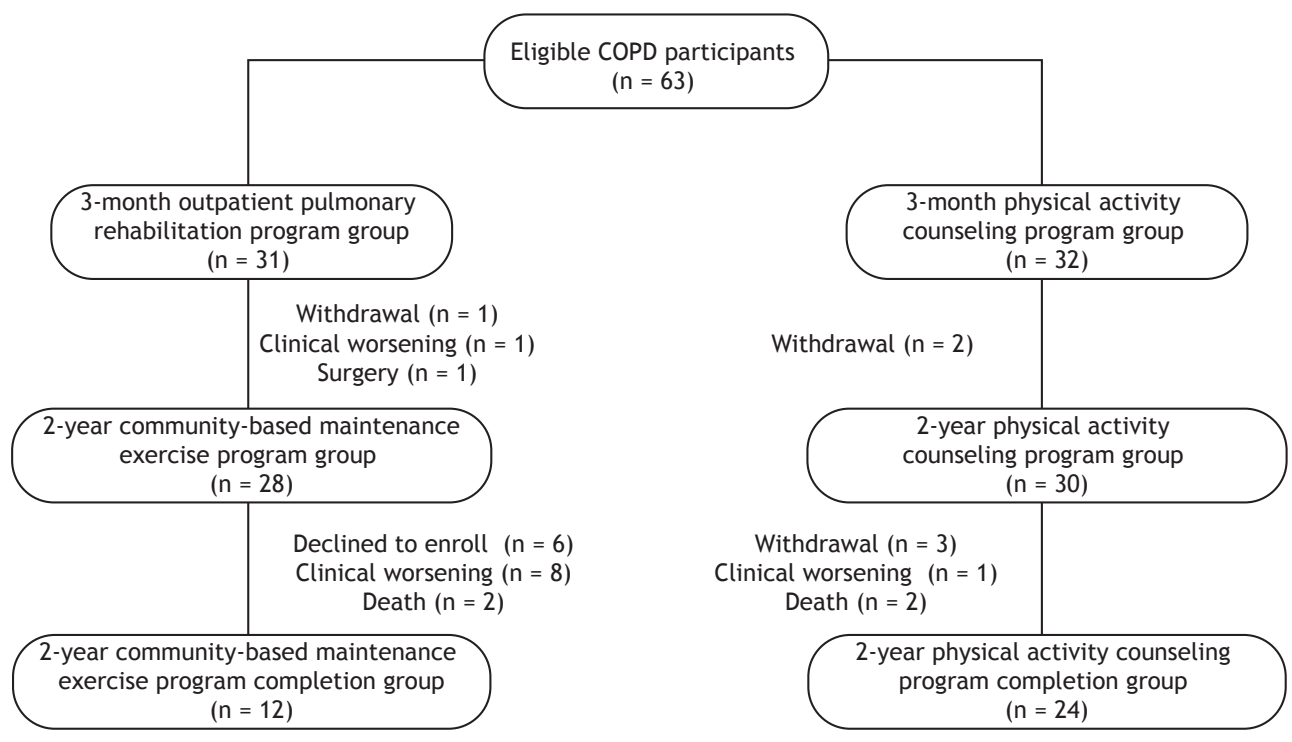

Figure 1. Flow chart for screening, recruitment, allocation, and intervention. 
Table 1. Clinical characteristics at baseline, by group. ${ }^{a}$

\begin{tabular}{lccc}
\hline Characteristic & $\begin{array}{c}\text { 24MME } \\
(\mathbf{n}=\mathbf{1 2})\end{array}$ & $\begin{array}{c}\text { 27MPAC } \\
(\mathbf{n}=\mathbf{2 4})\end{array}$ & $\mathbf{p}$ \\
\hline Age $(\mathrm{yr})$ & $64 \pm 6$ & $68.7 \pm 7.8$ & 0.14 \\
Weight $(\mathrm{kg})$ & $88.5 \pm 22.9$ & $80.5 \pm 14.3$ & 0.20 \\
BMl $\left(\mathrm{kg} / \mathrm{m}^{2}\right)$ & $30.8 \pm 6.6$ & $28.6 \pm 4.8$ & 0.25 \\
FEV $(\%)$ & $51.5 \pm 10.6$ & $46.8 \pm 15.5$ & 0.86 \\
FVC $(\%)$ & $78.8 \pm 16.7$ & $76.7 \pm 14.2$ & 0.68 \\
FEV $/$ FVC $(\%)$ & $47.2 \pm 7.0$ & $43.6 \pm 12.1$ & 0.85 \\
TLC $(\%)$ & $118.2 \pm 20.1$ & $117.2 \pm 22.0$ & 0.95 \\
6MWD $(\mathrm{m})$ & $553.3 \pm 63.4$ & $475.7 \pm 69.7$ & 0.01
\end{tabular}

24MME: 24-month community-based maintenance exercise program preceded by 3 months of outpatient pulmonary rehabilitation; 27MPAC: 27-month physical activity counseling program; BMI: body mass index; and 6MWD: six-

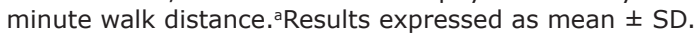

magnitude of improvement was greater in the 24MME group than in the 27MPAC group $(p<0.01)$.

At the end of the study period, the maximal strength in the chest press exercise was greater than the baseline value by $37.6 \pm 28.3 \%$ in the 24MME group (from 57.5 $\pm 16.7 \mathrm{~kg}$ to $76.2 \pm 15.2 \mathrm{~kg} ; \mathrm{p}<0.001)$ and by 8.8 $\pm 16 \%$ in the 27 MPAC group (from $59.7 \pm 13.2 \mathrm{~kg}$ to $63.9 \pm 12.9 \mathrm{~kg} ; \mathrm{p}=0.26)$, as can be seen in Figure 3. The magnitude of improvement was greater in the $24 M M E$ group than in the 27MPAC group ( $p<0.01$ ).

Over the course of the study period (from baseline to 3 months to the end of the study period), the 6MWD showed a significant time-dependent effect in the 24MME group (from $553.3 \pm 63.4 \mathrm{~m}$ to 586.6 $\pm 67.4 \mathrm{~m}$ to $570.5 \pm 97.9 \mathrm{~m}$; $\mathrm{p}<0.04)$, although not in the 27MPAC group (from $475.7 \pm 69.7 \mathrm{~m}$ to $478.7 \pm 77.6 \mathrm{~m}$ to $470.2 \pm 107.9 \mathrm{~m} ; \mathrm{p}=0.68$ ). From baseline to 3 months, the mean increase in the 6MWD was greater in the 24MME group than in the 27MPAC group (33.2 $\pm 36.6 \mathrm{~m}$ vs. $2.9 \pm 34.7 \mathrm{~m} ; \mathrm{p}<0.05)$, as shown in Figure 4.

As can be seen in Table 2, from baseline to 3 months, the changes in the CRQ scores for the dyspnea and mastery domains, as well as in the total score, were greater in the 24MME group than in the 27MPAC group $(p<0.05$ for all). At the end of the study period, there were no differences between the two groups in terms of the changes in the CRQ domain scores. From baseline to the end of the study period, all CRQ domain scores showed time-dependent effects in the 24MME group ( $p<$ $0.05)$, statistically significant improvements in the domain scores also being observed at 3 months ( $p<0.05)$.

\section{DISCUSSION}

The major findings of the present study were that the supervised, community-based maintenance exercise program preserved the benefits in maximal strength, muscle power, 6MWD, and quality of life obtained with $\mathrm{PR}$, and that the physical activity counseling program achieved greater gains in maximal strength at the end of the study period in comparison with the 3-month time point and improved the CRQ dyspnea domain score over the 24-month intervention period,

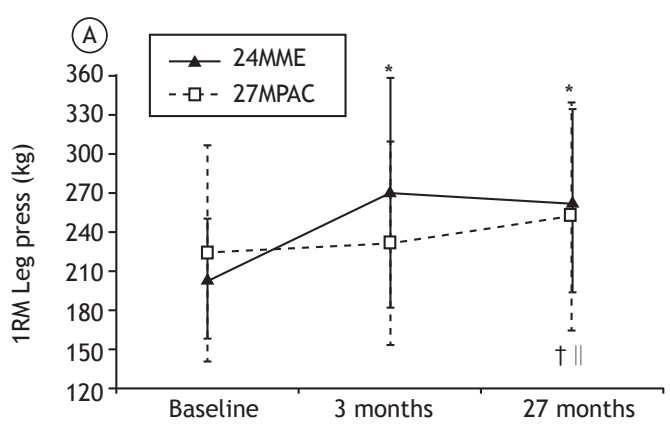

(B)

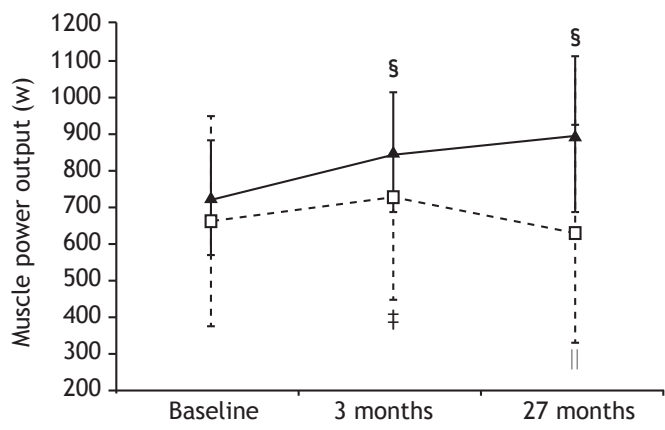

Figure 2. Maximal dynamic strength, defined as onerepetition maximum (1RM), in the leg press exercise (A) and muscle power output at $50 \%$ of the 1 RM in the leg press exercise (B), at the three time points evaluated, in the 24-month community-based maintenance exercise program preceded by 3 months of outpatient pulmonary rehabilitation (24MME) group and in the 27-month physical activity counseling program (27MPAC) group. $* p<0.001$ vs. baseline in the $24 \mathrm{MME}$ group. ${ }^{\dagger} p<0.01$ vs. baseline in the 27MPAC group. ${ }^{\ddagger} p<0.05$ vs. baseline in the 27 MPAC group. ${ }^{\S} p<0.05$ vs. baseline in the 24 MME group. " $p<$ 0.05 for 3 months vs. 27 months in the 27MPAC group.

as well as attenuating the decline in the 6MWD over that same period.

Skeletal muscle dysfunction has been postulated to be one of the extrapulmonary effects of COPD, resulting in reduced peripheral muscle strength, $(22,23)$ increased mortality risk, and decreased quality of life. ${ }^{(13,24)}$ Few studies have evaluated the maximal strength of the upper and lower limbs after two different long-term simple strategies have been applied in patients with COPD. In contrast with the findings 


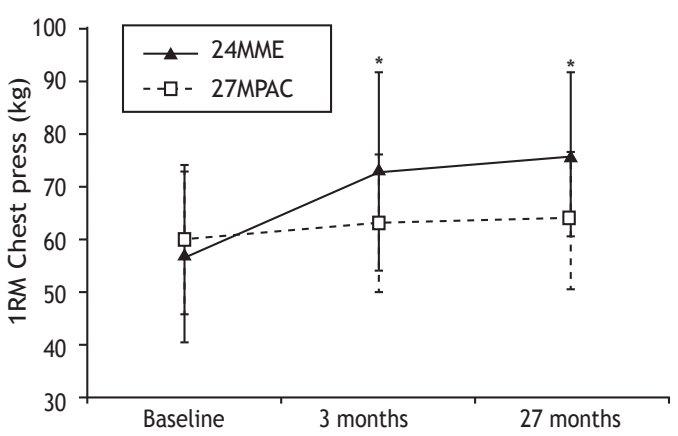

Figure 3. Maximal dynamic strength, defined as onerepetition maximum (1RM), on the chest press exercises, at the three time points evaluated, in the 24-month community-based maintenance exercise program preceded by 3 months of outpatient pulmonary rehabilitation (24MME) group and in the 27-month physical activity counseling program (27MPAC) group. $* p<0.001$ vs. baseline in the 24MME group.

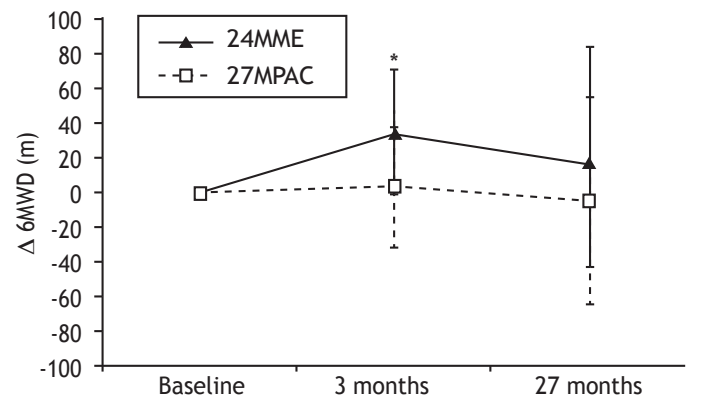

Figure 4. Changes in the six-minute walk distance $(\triangle 6 M W D$, in $\mathrm{m})$, in relation to the baseline measurement, in the 24-month community-based maintenance exercise program preceded by 3 months of outpatient pulmonary rehabilitation (24MME) group and in the 27 -month physical activity counseling program (27MPAC) group. *Significant difference between the two groups $(p<0.05)$.

of a previous study, ${ }^{(7)}$ which demonstrated no effects on maximal muscle strength after 20 months of an active maintenance phase, our results indicate that a supervised community-based maintenance exercise program preserved the PR-induced increases achieved in maximal strength of the upper and lower limbs over the 24-month intervention period. One unique finding was that, in the 27MPAC group, the maximal strength of the lower limbs was $13.6 \%$ higher at the end of the study period than at baseline. Our findings have important clinical implications. Waschki et al. ${ }^{(25)}$ reported that a sustained low level of physical activity is related to the progressive muscle depletion that occurs in all patients with COPD. Our findings suggest that a physical activity counseling program is an effective, simple strategy to attenuate the deconditioning of the peripheral muscles in the lower limbs in older men with COPD.

On the basis of our findings, it was not possible to identify the physiological mechanisms responsible for the difference between the maintenance exercise program and the physical activity counseling program in terms of the increase in the maximal strength of the lower limbs, which was greater after the former program. One possible explanation for our finding that the observed gains in the muscle strength of the lower limbs were lesser in the 27MPAC group than in the $24 \mathrm{MME}$ group is that the relative training intensity (40-70\% of the 1RM) was greater in the $24 \mathrm{MME}$ group than in the 27MPAC group. Another possible explanation is that, in older men with COPD, the 6MWD is positively associated with leg muscle power output, although not with maximal strength. (26) Taken together, our results suggest that a practicable, supervised, communitybased maintenance program is a satisfactory means of maintaining the benefits that PR provides in terms of maximal muscle strength in the upper and lower limbs; that a physical activity counseling program is a simple, effective strategy to attenuate peripheral muscle deconditioning in the lower limbs of older adult men with COPD; and that such individuals might require a specific strength training program.

The age-related decrease in maximal strength and explosive force production has been attributed to a loss of muscle mass mediated by a loss and a decrease in the size of individual muscle fibers. ${ }^{(27,28)}$ In the lower limbs of older adults, impaired muscle power output has recently emerged as a more important predictor of limitations to mobility in tasks, such as rising from a chair and climbing stairs, than is maximal muscle strength, lower-limb muscle power output also constituting a determinant of habitual walking speed and the risk of falls. ${ }^{(9,29-34)}$ To our knowledge, this is the first article to report the effects that long-term strategies have on the muscle power output of the lower limbs in older men with COPD. The results of the present study indicate that a community-based maintenance exercise program can maintain muscle power output for at least 24 months after PR. However, we found that muscle power output decreased by $15 \%$ after 3 months in the 27MPAC group. Our results suggest that a physical activity program for older men with COPD should include high-velocity muscle power training for the lower limbs, to attenuate the loss of muscle mass.

Our results are in agreement with those of previous studies reporting that the observed benefits of PR on exercise capacity and quality of life are maintained over a 24-month period with a supervised, communitybased exercise program. ${ }^{(4,5)}$ In the present study, we expanded our investigation by determining the effects that a physical activity counseling program had on exercise capacity and quality of life over a 27-month period. We found that the 24-month community-based maintenance exercise program maintained the benefits of PR in all CRQ domains, and that the 27-month physical activity counseling program resulted in improvement in the CRQ dyspnea domain. Two possible explanations for the difference between the two programs are the supervision and the intensity of the exercise in the 24-month community-based maintenance exercise program.

One important and clinically relevant finding of the present study is that there was no decline in the 
Table 2. Changes in Chronic Respiratory Questionnaire scores over time. ${ }^{a}$

\begin{tabular}{|c|c|c|c|}
\hline CRO score & $\begin{array}{c}24 \mathrm{MME} \\
\text { group }\end{array}$ & $\begin{array}{l}\text { 27MPAC } \\
\text { group }\end{array}$ & $\mathbf{p}$ \\
\hline \multicolumn{4}{|l|}{ Dyspnea domain } \\
\hline Baseline & $3.8 \pm 1.1$ & $4.0 \pm 1.1$ & 0.59 \\
\hline Month 3 & $4.9 \pm 1.3$ & $4.6 \pm 1.5$ & \\
\hline Month 27 & $5.1 \pm 1.2$ & $4.8 \pm 1.8$ & \\
\hline Change from baseline to 3 months & $1.2 \pm 0.7$ & $0.6 \pm 1.0$ & 0.04 \\
\hline Change from baseline to 27 months & $1.3 \pm 0.7$ & $0.8 \pm 1.8$ & 0.23 \\
\hline Time-dependent effect (baseline vs. 27 months) & $<0.001$ & 0.07 & \\
\hline \multicolumn{4}{|l|}{ Fatigue (points) } \\
\hline Baseline & $5.1 \pm 1.1$ & $5.1 \pm 0.8$ & 0.83 \\
\hline Month 3 & $5.7 \pm 1.5$ & $5.3 \pm 1.0$ & \\
\hline Month 27 & $5.7 \pm 0.9$ & $5.4 \pm 1.1$ & \\
\hline Change from baseline to 3 months & $0.6 \pm 0.9$ & $0.2 \pm 0.7$ & 0.14 \\
\hline Change from baseline to 27 months & $0.7 \pm 0.8$ & $0.3 \pm 1.1$ & 0.43 \\
\hline Time-dependent effect (baseline vs. 27 months) & 0.03 & 0.14 & \\
\hline \multicolumn{4}{|l|}{ Emotional (points) } \\
\hline Baseline & $4.9 \pm 1.4$ & $5.4 \pm 1.0$ & 0.33 \\
\hline Month 3 & $5.7 \pm 1.3$ & $5.7 \pm 1.1$ & \\
\hline Month 27 & $5.9 \pm 0.8$ & $5.7 \pm 1.2$ & \\
\hline Change from baseline to 3 months & $0.8 \pm 0.8$ & $0.4 \pm 0.7$ & 0.16 \\
\hline Change from baseline to 27 months & $0.9 \pm 1.0$ & $0.4 \pm 0.8$ & 0.10 \\
\hline Time-dependent effect (baseline vs. 27 months) & 0.02 & 0.18 & \\
\hline \multicolumn{4}{|l|}{ Mastery (points) } \\
\hline Baseline & $5.5 \pm 1.5$ & $6.4 \pm 0.5$ & 0.09 \\
\hline Month 3 & $6.2 \pm 1.4$ & $6.4 \pm 0.8$ & \\
\hline Month 27 & $6.4 \pm 0.8$ & $6.4 \pm 0.8$ & \\
\hline Change from baseline to 3 months & $0.7 \pm 1.0$ & $0.0 \pm 0.5$ & 0.02 \\
\hline Change from baseline to 27 months & $0.4 \pm 1.3$ & $-0.02 \pm 0.6$ & 0.09 \\
\hline Time-dependent effect (baseline vs. 27 months) & $<0.01$ & 0.83 & \\
\hline \multicolumn{4}{|l|}{ CRQ Total Score (points) } \\
\hline Baseline & $19.3 \pm 4.6$ & $20.5 \pm 2.7$ & 0.34 \\
\hline Month 3 & $22.6 \pm 5.1$ & $21.6 \pm 3.5$ & \\
\hline Month 27 & $22.6 \pm 4.0$ & $21.8 \pm 3.8$ & \\
\hline Change from baseline to 3 months & $3.3 \pm 2.9$ & $1.1 \pm 2.1$ & 0.01 \\
\hline Change from baseline to 27 months & $3.3 \pm 1.5$ & $1.3 \pm 3.1$ & 0.047 \\
\hline Time-dependent effect (baseline vs. 27 months) & 0.001 & 0.055 & \\
\hline
\end{tabular}

CRQ: Chronic Respiratory Questionnaire; 24MME: 24-month community-based maintenance exercise program preceded by 3 months of outpatient pulmonary rehabilitation; and 27MPAC: 27-month physical activity counseling program. aResults expressed as mean \pm SD.

6MWD during the study period in the 27MPAC group. In addition, there were no significant differences between the two groups in terms of the changes in the 6MWD at the end of the study period. In the present study, no gains in the 6MWD were observed in the 27MPAC group. That differs from what has been found in previous studies, $(6,35,36)$ in which improvements in the 6MWD were observed after 3 months of physical activity counseling. These discrepancies could be explained by the fact that some previous studies have used a pedometer during the intervention and have set goals for their participants, ${ }^{(6,35,36)}$ some even using a semiautomated telecoaching program. ${ }^{(35)}$ Taken together, these results suggest that a physical activity counseling program could prevent the predicted decline in the 6MWD (35 $\mathrm{m} /$ year) for patients who are physically inactive. ${ }^{(25)}$
Our experimental approach has several methodological limitations. First, ours was a prospective study involving two independent, single-arm trials without randomization. In addition, the sample size was small. Furthermore, all of the participants were male, and the results therefore cannot be extrapolated to females. In Spain, the prevalence of COPD, as defined by the Global Initiative for Chronic Obstructive Lung Disease criteria, is higher in men than in women (15.1\% vs. $5.6 \%)$. $^{(37)}$ Moreover, the dropout rate was greater in the $24 \mathrm{MME}$ group than in the 27 MPAC group ( $57 \%$ vs. $20 \%$ ). Six of the 24MME group participants declined to continue the maintenance exercise program, and most of the 24MME group participants who dropped out of the program did so because of clinical worsening during 
the intervention period. In each of the two groups, there were 2 participants who died during the study period (Figure 1). However, in comparison with that reported in previous studies, ${ }^{(4)}$ the dropout rate in the present study was not unusual, especially considering the duration of the intervention period. Finally, the 24-month community-based maintenance exercise program was preceded by outpatient PR program, whereas the 27-month physical activity counseling program was not, and there were no measurements taken at one year in.
In conclusion, the results of the present study indicate that a 24-month, supervised community-based maintenance exercise program provides a significant training stimulus to preserve the gains in maximal strength, muscle power, 6MWD, and quality of life observed after 3 months of PR in older men with COPD. A 27-month physical activity counseling program results in improvements in maximal muscle strength of the lower limbs and may be an effective, simple strategy to attenuate peripheral muscle dysfunction and maintain exercise capacity in older men with COPD.

\section{REFERENCES}

1. Griffiths TL, Burr ML, Campbell IA, Lewis-Jenkins V, Mullins J Shiels $\mathrm{K}$, et al. Results at 1 year of outpatient multidisciplinary pulmonary rehabilitation: a randomised controlled trial. Lancet. 2000:355(9201):362-8. http://dx.doi.org/10.1016/S01406736(99)07042-7

2. Moullec G, Ninot G, Varray A, Desplan J, Hayot M, Prefaut C. An innovative maintenance follow-up program after a first inpatient pulmonary rehabilitation. Respir Med. 2008;102(4):556-66. https:// doi.org/10.1016/j.rmed.2007.11.012

3. Beauchamp MK, Evans $R$, Janaudis-Ferreira $T$, Goldstein RS Brooks D. Systematic review of supervised exercise programs after pulmonary rehabilitation in individuals with COPD. Chest 2013;144(4):1124-33. https://doi.org/10.1378/chest.12-2421

4. Güell MR, Cejudo P, Ortega F, Puy MC, Rodríguez-Trigo G, Pijoan JI, et al. Benefits of Long-Term Pulmonary Rehabilitation Maintenance Program in Severe Chronic Obstructive Pulmonary Disease. ThreeYear Follow-up. Am J Respir Crit Care Med. 2017;195(5):622-29. https://doi.org/10.1164/rccm.201603-0602OC

5. Güell R, Casan P, Belda J, Sangenis M, Morante F, Guyatt GH et al. Long-term effects of outpatient rehabilitation of COPD: A randomized trial. Chest. 2000;117(4):976-83. http://dx.doi org/10.1378/chest.117.4.976

6. Altenburg WA, ten Hacken NH, Bossenbroek L, Kerstjens HA, de Greef $\mathrm{MH}$, Wempe JB. Short- and long-term effects of a physical activity counselling programme in COPD: a randomized controlled trial. Respir Med. 2015;109(1):112-21. https://doi.org/10.1016/j. rmed.2014.10.020

7. van Wetering CR, Hoogendoorn M, Mol SJ, Rutten-van Mölken MP, Schols AM. Short- and long-term efficacy of a communitybased COPD management programme in less advanced COPD: a randomised controlled trial. Thorax. 2010;65(1):7-13. http://dx.doi org/10.1136/thx.2009.118620

8. Seymour JM, Spruit MA, Hopkinson NS, Natanek SA, Man WD, Jackson $A$, et al. The prevalence of quadriceps weakness in COPD and the relationship with disease severity. Eur Respir J 2010;36(1):81-8. https://doi.org/10.1183/09031936.00104909

9. Izquierdo M, Ibañez J, Gorostiaga E, Garrues M, Zúñiga A, Antón A, et al. Maximal strength and power characteristics in isometric and dynamic actions of the upper and lower extremities in middle-aged and older men. Acta Physiol Scand. 1999;167(1):57-68. https://doi org/10.1046/j.1365-201x.1999.00590.x

10. Evans WJ, Hurley BF. Age, gender, and muscular strength. J Gerontol A Biol Sci Med Sci. 1995;50 Spec No:41-4. https://doi. org/10.1093/gerona/50A.Special_Issue.41

11. American College of Sports Medicine, Chodzko-Zajko WJ, Proctor DN, Fiatarone Singh MA, Minson CT, Nigg CR, et al. American College of Sports Medicine position stand. Exercise and physical activity for older adults. Med Sci Sports Exerc. 2009;41(7):1510-30. https://doi.org/10.1249/MSS.0b013e3181a0c95c

12. Hunter GR, McCarthy JP, Bamman MM. Effects of resistance training on older adults. Sports Med. 2004:34(5):329-48. https://doi. org/10.2165/00007256-200434050-00005

13. Marquis K, Debigaré R, Lacasse $Y$, LeBlanc $P$, Jobin J, Carrier G, et al. Midthigh muscle cross-sectional area is a better predictor of mortality than body mass index in patients with chronic obstructive pulmonary disease. Am J Respir Crit Care Med. 2002;166(6):809-13. https://doi. org/10.1164/rccm.2107031

14. Reid KF, Fielding RA. Skeletal muscle power: a critical determinant of physical functioning in older adults. Exerc Sport Sci Rev. 2012;40(1):4
12. https://doi.org/10.1097/JES.0b013e31823b5f13

15. Abizanda Soler P, López-Torres Hidalgo J, Romero Rizos L, López Jiménez M, Sánchez Jurado PM, Atienzar Núñez $\mathrm{P}$, et al. Frailty and dependence in Albacete (FRADEA study): reasoning, design and methodology [Article in Spanish]. Rev Espanola Geriatr Gerontol. 2011;46(2):81-8. https://doi.org/10.1016/j.regg.2010.10.004

16. Vestbo J, Hurd SS, Agustí AG, Jones PW, Vogelmeier C, Anzueto A et al. Global strategy for the diagnosis, management, and prevention of chronic obstructive pulmonary disease: GOLD executive summary. Am J Respir Crit Care Med. 2013;187(4):347-65. https:// doi.org/10.1164/rccm.201204-0596PP

17. ATS Committee on Proficiency Standards for Clinical Pulmonary Function Laboratories. ATS statement: guidelines for the six-minute walk test. Am J Respir Crit Care Med. 2002;166(1):111-7. https://doi. org/10.1164/ajrccm.166.1.at1102

18. Guyatt GH, Berman LB, Townsend M, Pugsley SO, Chambers LW. A measure of quality of life for clinical trials in chronic lung disease. Thorax. 1987;42(10):773-8. http://dx.doi.org/10.1136/thx.42.10.773

19. Güell R, Casan P, Sangenís M, Morante F, Belda J, Guyatt GH Quality of life in patients with chronic respiratory disease: the Spanish version of the Chronic Respiratory Questionnaire (CRQ). Eur Respir J. 1998;11(1):55-60.

20. Izquierdo M, Ibañez J, HAkkinen K, Kraemer WJ, Larrión JL, Gorostiaga EM. Once weekly combined resistance and cardiovascular training in healthy older men. Med Sci Sports Exerc. 2004;36(3):435 43. http://dx.doi.org/10.1249/01.MSS.0000117897.55226.9A

21. Zambom-Ferraresi F, Cebollero P, Gorostiaga EM, Hernández M Hueto J, Cascante J, et al. Effects of Combined Resistance and Endurance Training Versus Resistance Training Alone on Strength Exercise Capacity, and Quality of Life in Patients With COPD. J Cardiopulm Rehabil Prev. 2015;35(6):446-53. https://doi.org/10.1097/ HCR.0000000000000132

22. Bernard S, LeBlanc P, Whittom F, Carrier G, Jobin J, Belleau R, et al. Peripheral muscle weakness in patients with chronic obstructive pulmonary disease. Am J Respir Crit Care Med. 1998;158(2):629-34 https://doi.org/10.1164/ajrccm.158.2.9711023

23. Gosker HR, Kubat B, Schaart G, van der Vusse GJ, Wouters EF, Schols AM. Myopathological features in skeletal muscle of patients with chronic obstructive pulmonary disease. Eur Respir J. 2003;22(2):280-5. https://doi.org/110.1183/09031936.03.00012803

24. Decramer M, Gosselink R, Troosters T, Verschueren M, Evers G. Muscle weakness is related to utilization of health care resources in COPD patients. Eur Respir J. 1997;10(2):417-23.

25. Waschki B, Kirsten AM, Holz O, Mueller KC, Schaper M, Sack AL, et al. Disease Progression and Changes in Physical Activity in Patients with Chronic Obstructive Pulmonary Disease. Am J Respir Crit Care Med. 2015;192(3):295-306. https://doi.org/10.1164/rccm.20150100810C

26. Hernández M, Zambom-Ferraresi F, Cebollero P, Hueto J, Cascante JA, Antón MM. The Relationships between Muscle Power and Physical Activity in Older Men with Chronic Obstructive Pulmonary Disease. J Aging Phys Act. 2017;25(3):360-366. https://doi. org/10.1123/japa.2016-0144

27. Larsson L. Morphological and functional characteristics of the ageing skeletal muscle in man. A cross-sectional study. Acta Physiol Scand Suppl. 1978:457:1-36.

28. Lexell J. Ageing and human muscle: observations from Sweden. Can J Appl Physiol. 1993;18(1):2-18. https://doi.org/10.1139/h93-002 
29. Izquierdo M, Aguado X, Gonzalez R, López JL, Häkkinen K. Maximal and explosive force production capacity and balance performance in men of different ages. Eur J Appl Physiol Occup Physiol. 1999;79(3):260-7. https://doi.org/10.1007/s004210050504

30. Bassey EJ, Fiatarone MA, O'Neill EF, Kelly M, Evans WJ, Lipsitz LA Leg extensor power and functional performance in very old men and women. Clin Sci (Lond). 1992;82(3):321-7. https://doi.org/10.1042/ cs0820321

31. Bean JF, Leveille SG, Kiely DK, Bandinelli S, Guralnik JM, Ferrucci L. A comparison of leg power and leg strength within the InCHIANTI study: which influences mobility more? J Gerontol A Biol Sci Med Sci. 2003;58(8):728-33. https://doi.org/10.1093/gerona/58.8.M728

32. Bean JF, Kiely DK, Herman S, Leveille SG, Mizer K, Frontera WR, et al. The relationship between leg power and physical performance in mobility-limited older people. J Am Geriatr Soc. 2002;50(3):461-7. https://doi.org/10.1046/j.1532-5415.2002.50111.x

33. Cadore EL, Casas-Herrero A, Zambom-Ferraresi F, Idoate F, Millor $\mathrm{N}$, Gómez $\mathrm{M}$, et al. Multicomponent exercises including muscle power training enhance muscle mass, power output, and functional outcomes in institutionalized frail nonagenarians. Age (Dordr).
2014;36(2):773-85. https://doi.org/10.1007/s11357-013-9586-z

34. Casas-Herrero A, Cadore EL, Zambom-Ferraresi F, Idoate F, Millor N, Martínez-Ramirez A, et al. Functional capacity, muscle fat infiltration, power output, and cognitive impairment in institutionalized frail oldest old. Rejuvenation Res. 2013;16(5):396-403. https://doi. org/10.1089/rej.2013.1438

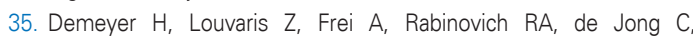
Gimeno-Santos $\mathrm{E}$, et al. Physical activity is increased by a 12-week semiautomated telecoaching programme in patients with COPD: a multicentre randomised controlled trial. Thorax. 2017;72(5):415-23. http://dx.doi.org/10.1136/thoraxjnl-2016-209026

36. Mendoza L, Horta P, Espinoza J, Aguilera M, Balmaceda N, Castro $A$, et al. Pedometers to enhance physical activity in COPD: randomised controlled trial. Eur Respir J. 2015;45(2):347-54. https:// doi.org/10.1183/09031936.00084514

37. Miravitlles M, Soriano JB, García-Río F, Muñoz L, Duran-Tauleria E, Sanchez G, et al. Prevalence of COPD in Spain: impact of undiagnosed COPD on quality of life and daily life activities. Thorax. 2009;64(10):863-8. https://doi.org/10.1136/thx.2009.115725 